\title{
Neurological involvement in incontinentia pigmenti
}

\author{
Mustafa Aydin • Nilay Hakan • Nihal Demirel • \\ Ugur Deveci • Aysegul Zenciroglu • Nurullah Okumus
}

Received: 31 July 2013 / Accepted: 26 September 2013 /Published online: 6 October 2013

(C) Springer-Verlag Berlin Heidelberg 2013

\section{Dear Editor,}

We read with great interest the article by Zhang et al. [4] that reported on cutaneous manifestations of incontinentia pigmenti (IP) with blisters on the trunk and limbs, sparing the face, in a 15day-old female infant. Incontinentia pigmenti is a rare, X-linked dominant multisystem genodermatosis affecting ectodermal and mesodermal tissues. It is often associated with cutaneous, ocular, dental, and central nervous system (CNS) abnormalities [3]. After the skin, the central nervous system is the second most affected system. But, we did not see the neurological findings of the presented case. Because IP is one of neurocutaneous disorders, we aimed to emphasize the neurological involvement in IP.

Recently, we reported on a female infant at the age of day 5 with IP that had marked neurological involvement [2]. Contrary to presented case, a family history was positive in our patient. Additionally, pedigree of the family indicated early losses of male fetuses. Similarly, our patient had erythematous vesicles arranged in linear groups involving mainly the limbs and the trunk, and also an encephalocele on the vertex plane of the patient's head. The mother's examination revealed cutaneous atrophic hypopigmented lesions. Cranial magnetic resonance

M. Aydin · U. Deveci

Division of Neonatology, Department of Pediatrics, Elazig Training and Research Hospital, Elazig, Turkey

\section{N. Hakan ( ()}

Division of Neonatology, Department of Pediatrics, Erzurum

Training and Research Hospital, Erzurum, Turkey

e-mail: nhakan@hotmail.com

\section{N. Demirel}

Division of Neonatology, Department of Pediatrics, Ankara Etlik Maternity and Women's Health Teaching Research Hospital, Ankara, Turkey

A. Zenciroglu $\cdot$ N. Okumus

Division of Neonatology, Department of Pediatrics, Dr. Sami Ulus Maternity and Children Hospital, Ankara, Turkey imaging (MRI) of the patient revealed a midline skull defect on the posterior parietal bone and an associated protruding lesion consistent with encephalocele. In addition, agenesis of the corpus callosum, an arachnoid cyst in the posterior fossa, a porencephalic cyst in the left parietal lobe, and diffuse contrast uptake on the tentorium were demonstrated.

Up to half of patients with IP are reported to have evidence of CNS involvement. The most common manifestations of CNS involvement are microcephaly, hydrocephalus, strokes, seizures, global developmental delay, spastic paresis, cerebellar ataxia, and MRI changes [1]. However, encephalocele, which is first reported in our case, was not defined previously. The CNS manifestations of our patient were similar to findings of previous reports, except the presence of an encephalocele. Seizures can be the presenting symptom of the disease and usually develop within the first few weeks of life.

The CNS involvement is a very important issue for predicting the prognosis in patients with IP. These patients should be regularly followed up for possible development of neurological handicaps, like epileptic seizures.

Conflict of interest The authors report that there is no any conflict of interest and any financial relationship.

\section{References}

1. Aydingöz U, Midia M (1998) Central nervous system involvement in incontinentia pigmenti: cranial MRI of two siblings. Neuroradiology 40:364-366

2. Demirel N, Aydin M, Zenciroglu A, Okumus N, Tekgunduz KS, Ipek MS, Boduroglu E (2009) Incontinentia pigmenti with encephalocele in a neonate: a rare association. J Child Neurol 24:495-499

3. Nogueira A, Lisboa C, Eloy C, Mota A, Azevedo F (2009) Vesicular rash in a newborn. Incontinentia pigmenti. Indian J Dermatol Venereol Leprol 75:330

4. Zhang Y, Pyla V, Cong X (2013) Incontinentia pigmenti (BlochSiemens syndrome). Eur J Pediatr 172:1137-1138. doi:10.1007/s00431013-1982-y 